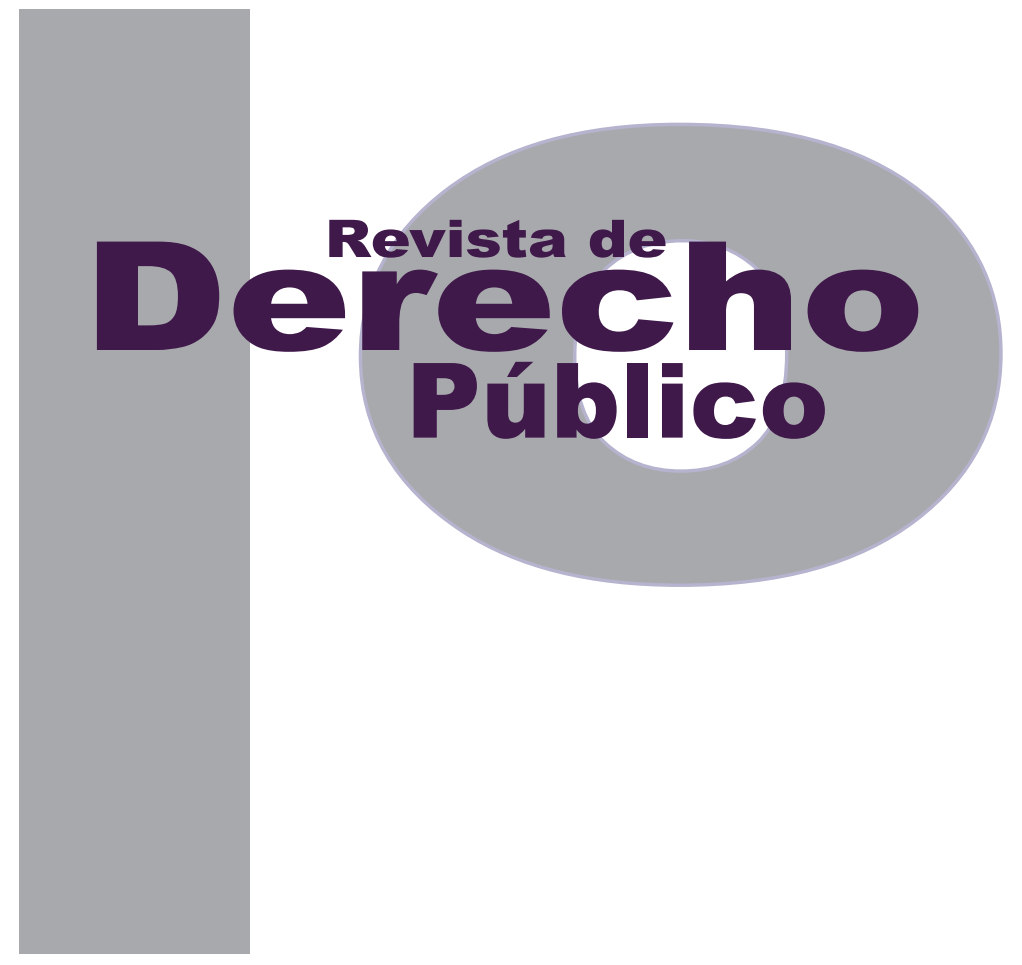

\title{
El círCulo (LOS LAZOS) DE LA PALABRA
}

\author{
BEATRIZ BOTERO ARCILA
}

Universidad de los Andes

Facultad de Derecho

Revista de Derecho Público N. ${ }^{\circ} 32$

Enero - Junio de 2014. ISSN 1909-7778 


\title{
El círculo (los lazos) de la palabra*
}

\author{
Beatriz Botero Arcila**
}

\section{RESUMEN}

Durante la segunda mitad del siglo XX los ordenamientos jurídicos occidentales se enfrentaron, como quizá nunca antes, a la pregunta sobre lo ético en lo jurídico y asumieron posturas y vocabularios éticos buscando garantizar ordenamientos jurídicos más justos y menos manipulables. En este artículo la autora propone la adopción de discursos éticos que no tengan un vocabulario ni premisas comunes con el lenguaje jurídico actual, como la ética de Levinas, para evitar que los estándares éticos y jurídicos se confundan. Detrás de la propuesta está la ilusión de crear ordenamientos lo más justos e incluyentes posibles, desprovistos de prejuicios.
During the second half of the XXth Century, the legal systems of the west faced like never before the question of the relevance of ethics in the Law and they adopted the values and the vocabulary of the ethics in order to seek for more just and less malleable legal systems. In this article, the author proposes the adoption of ethical theories that do not have a common vocabulary or common premises with the contemporary legal language, additionally to the traditional ethical theories, such as the ethics of Levinas. Behind this proposal lies the project of a legal system deeply just and inclusive, deprive of any prejudices at all.

Cómo citar este artículo: Botero, B. (junio, 2014). El círculo (los lazos) de la palabra. Revista de Derecho Público, 32.

Este texto se escribió para el curso de Ética Profesional de Facultad de Derecho de la Universidad de los Andes en el año 2012.

Estudiante de octavo semestre de Derecho en la Universidad de los Andes y de piano clásico en la Universidad Javeriana. A lo largo de su carrera se ha interesado por una diversidad de temas jurídicos. Ha sido monitora de los cursos de Derecho Romano, Introducción al Derecho y Derecho Internacional Público. Asimismo, ha trabajado en el Centro de Estudios de Derecho, justicia y Sociedad como asistente de comunicaciones y como asistente de investigación no graduada, realizó un intercambio académico en el Center for Transnational Legal Suties (CTLS) de Georgetown University en Londres y fue pasante de verano en la firma de abogados Brigard y Urrutia en el 2013. Beatriz disfruta, además, particularmente de la escritura. Ha escrito para revistas virtuales como KienyKe y Las2orillas, mantiene un blog y es miembro del comité editorial del periódico AIDerecho, del cual fue directora durante el segundo semestre del año 2012. Correo: b.botero250@uniandes.edu.co 
Palabras clave: teoría del derecho, ética, justicia, Emmanuel Levinas, derecho, iusnaturalismo, positivismo, círculo de la palabra, Matar un ruiseñor, Atticus Finch.
KEY WORDS: theory of law, ethics, justice, Emmanuel Levinas, law, natural law, positivism, circle the word, To Kill a Mockingbird, Atticus Finch. 
SUMARIO

Introducción - I. PUNTO DE PARTIDA: EL DERECHO CAMBIA - II. EI PROBLEMA - III. LA ÉTICA DE LEVINAS COMO LENTE - IV. LA PROPUESTA - V. UN ESTUDIO DE CASO: ATTICUS FINCH - VI. EL CÍRCULO DE LA PALABRA Y CONCLUSIÓN. 
Introducción

“The one thing that doesn't abide by majority rule is a person's conscience."

Palabras dichas por Atticus Finch, en la obra de Harper

Lee: To Kill a Mockingbird.

\section{PUNTO DE PARTIDA: EL DERECHO CAMBIA}

Quizá uno de los principales problemas que se enfrentan al adoptar un ordenamiento jurídico como propio, sobre todo cuando se es abogado o parte operante de este, es saberlo imperfecto y quizás falible. Pensar o incluso creer que el orden que nos gobierna puede estar equivocado puede llegar a ser desolador o, al menos, inquietante. Es un problema tanto de legitimidad como de confianza. No se trata, a este nivel, de sus expresiones concretas, como una norma, la nueva jugada del Congreso, la redacción del Código civil o la multa del policía -aunque es quizá aquí donde diariamente manifestamos nuestra distancia con el ordenamiento jurídico- sino de sus fundamentos, de los principios mismos del ordenamiento jurídico, de sus axiomas y sus consecuencias.

¿Qué tal que no todos los hombres sean iguales y que haya vidas más valiosas que otras? El preámbulo de la Constitución de 1991 o la Declaración de los Derechos Humanos estarían, fundamentalmente, errados. ¿Qué tal que la personalidad jurídica y la propiedad no debieran ser protegidas por el orden más justo posible? ¿Qué tal que el consentimiento y la voluntad sean inexistentes y que, en realidad, los seres humanos no tengamos ningún control sobre nuestras acciones? Las anteriores son preguntas que cuestionan las premisas que asumimos como ciertas para fundamentar nuestras reglas y valores: la responsabilidad, la culpa, el respeto por el otro, la libre voluntad. Me dirán, con razón, que estos postulados básicos se han venido puliendo por la historia y que si bien es imposible afirmar que sean "verdaderos", porque ¿qué es "la verdad" al fin de cuentas?, son ideas que se han perfeccionado a lo largo de miles de años y de miles de experiencias históricas para organizar nuestra vida en sociedad y que así han ido probando al menos su validez y utilidad como fundamentos de un orden social.

En realidad, un ordenamiento jurídico es justamente eso: un orden social, y en esa medida adopta los postulados que son útiles a la sociedad que gobierna. En las sociedades de hoy, así como funcionan o como están, no tiene ningún sentido decir, por ejemplo, que hay un destino fijo y que todos nacemos determinados, porque en ese caso sería imposible hablar de "culpables" de un daño o de un crimen. Pero, por otro lado, una mirada al derecho en la historia revela que a medida que las sociedades evolucionan y que sus necesidades cambian sus valores también lo hacen y que esto no tiene nada de sorprendente.

Dada la inminencia del cambio y la altísima posibilidad de que en un par de siglos los valores de nuestro orden jurídico hayan evolucionado, otros hayan surgido y varios desaparecido, una buena pregunta es cómo evaluar y dirigir estos 
cambios de la mejor manera posible. La política y la democracia juegan, por supuesto, un papel esencial en la evolución de un orden jurídico, pero la sociología, la antropología, la economía $y$, por supuesto, la ética son también herramientas esenciales. Por su parte, la respuesta a cómo evaluar esos cambios son esas mismas disciplinas pero, con especial particularidad, la ética.

\section{EL PROBLEMA}

Ahora, la conexión y la pregunta sobre la relación entre el derecho y la justicia han estado siempre presentes. No obstante, en el siglo XX esta discusión tomó una importancia trascendental para la historia moderna posiblemente como resultado de los acontecimientos que tuvieron lugar en la Alemania Nazi y en la Segunda Guerra Mundial. Así, al menos en Occidente, se readoptó un lenguaje ético como una parte fundamental de la estructura del derecho escrito, por contraposición al antiguo y entonces algo relegado derecho natural. Así, se pasó a hablar de "derechos humanos e inalienables", "dignidad", "discriminación" y justicia, adoptamos de nuevo una forma de iusnaturalismo.

En este artículo sostengo que este fenómeno tiene como efecto colateral secundario la superposición de los dos planos: "lo ético" y “lo jurídico" y que como resultado de esto es posible que por referirnos a lo que es (o debería ser) éticamente correcto tendamos a recurrir a argumentos jurídicos. Esto sucede, por ejemplo, cuando afirmamos que "las mujeres tienen los mismos derechos que los hombres porque nacen iguales según la Constitución X y la Declaración Universal de los Derechos Humanos". Simultáneamente, también recurrimos a argumentos éticos para defender lo jurídico.

Ahora, esto es, por supuesto, hasta cierto punto inescapable y quizás necesario. Pero también es posible que, asumiendo que el derecho es cambiante, y la ética lo es menos, al menos partiendo de una visión más epistemológica que relativista de lo que es la ética, menos inestable y más absoluta, esta identidad de lenguajes y argumentos, así sea tan solo en un plano informal pero bastante común, puede eventualmente llegar a politizar la ética si, por descuido, se invierten los papeles y lo jurídico se vuelve lo bueno.

Así, mi intención en este artículo es plantear la necesidad de volver a separar la ética del derecho, como lo hicieron los positivistas a principios del siglo $\mathrm{XX}$, al menos como ejercicio teórico. Con ello no pretendo sugerir la posibilidad de un derecho inmoral (lo que es, quizá, el resultado de una mala lectura del positivismo de Kelsen), sino todo lo contrario: desde mi propuesta, pretendo proponer un rasero ético con el cual medir un ordenamiento jurídico. Se trata de tener una forma de marcar claros límites y una fuente para renovarlo, si es el caso, externa a él mismo. Este rasero es sugerido, entonces, desde la ética de Emmanuel Levinas, que presentaré rústicamente en el primer apartado; el ejercicio profesional de Atticus Finch, como un ejemplo de lo que propongo; $y$, por último, desde quizá una de las prácticas más antiguas de la humanidad: el círculo de la palabra. 


\section{LA ÉTICA DE LEVINAS COMO}

LENTE

Originalmente de Lituania y judío, Emmanuel Levinas sobrevivió al holocausto y dedicó el resto de su trabajo filosófico, profundamente influenciado por la fenomenología, a entender la posibilidad de una crueldad de la magnitud de la que fue víctima y testigo. ${ }^{1}$

Así, el punto de partida de Levinas es que una teoría ética que se funde en la igualdad y en el libre albedrío, que viene desde la Ilustración y de la ética kantiana, fracasa al intentar explicar un acontecimiento tal como el holocausto: por un lado la ética "tradicional" descarta de plano la diferencia (pues todos somos iguales), y sin embargo, un argumento clave en el holocausto fue que judíos y arios eran distintos. De esta manera, una mala lectura del sistema ético-valorativo fundado en la igualdad permite que este sea de exclusiva aplicación para los que somos iguales (que podría haber sido una lectura nazi). De la misma manera, una ética fundamentada en el libre albedrío descarta la posibilidad de, al menos, contemplar que todos seamos fruto de relaciones de fuerza históricas que determinen de alguna medida nuestras acciones.

Ahora, en ningún caso pretendo abarcar la filosofía de Levinas en este artículo. Simplemente tomo de ella nociones y conceptos que pueden

1 Todas las referencias a Levinas en el presente texto se basan en su libro Totalidad e Infinito. Son, no obstante, bastante básicas y en ningún caso pretendo estar abarcando la totalidad del contenido del libro. Siguiendo el lenguaje del autor, utilizaré la palabra sagrado pero sin ninguna connotación religiosa. Lo sagrado es lo infinito, lo intocable y, por ello, lo más valioso. ser interesantes a la hora de evaluar críticamente la justicia de un sistema jurídico. Este artículo es tan solo un esbozo de esto y no me refiero en él, tampoco, a lo fundamental de su filosofía.

Levinas descarta la posibilidad de pensar la ética a partir de la identidad del individuo y del libre albedrío. Desde la necesidad de pensar la ética de una manera distinta, una manera que permita responder a este tipo de acontecimientos, Levinas propone abordar el discurso ético no desde la identidad sino desde la alteridad, no desde el pensar que somos iguales, sino que somos profundamente diferentes. Pensar al otro como un fenómeno externo a mí que, no solo es diferente, sino que me es inabordable en su totalidad, que su realidad me es incomprensible y, por ello, sagrada. El otro es un interlocutor y quizá la forma de abordarlo es el lenguaje (Levinas, 2002, pág. 208). El tradicional "ponerse en los zapatos del otro" se vuelve prácticamente imposible y se pasa a asumir una actitud de profundo respeto ante la vida del otro (su actuar, su forma de ser) porque ese otro tiene un universo infinito detrás, que de ninguna manera le es concebible al yo - a mí. De ahí que su ética sea, en sus propias palabras, más que un sistema de reglas, una óptica (Levinas, 2002, pág. 50).

Ahora, que el otro sea inabarcable no significa necesariamente que esté infinitamente alejado. Levinas define la paz como la posibilidad de entablar una relación originaria con el otro (es decir, con lo que el otro es en lo más profundo) a través de la palabra y de la mirada. Para él esos dos fenómenos pueden romper la infinita distancia que hay entre dos personas y son un 
atisbo a la infinitud del otro, son el punto de encuentro con el otro. ${ }^{2}$ La guerra es, en contraposición, la interacción de fuerzas. La política es, de hecho, una expresión de la guerra.

La consecuencia de abordar las relaciones humanas desde este punto de vista tan respetuoso es, entre otras, que se vuelve enormemente difícil emitir cualquier tipo de juicio sobre una persona o su modo de actuar u ordenar determinadas acciones. ${ }^{3}$ En términos jurídicos, podría casi decirse que los mandatos éticos pasan de ser varias obligaciones de hacer y no hacer, guiadas quizá por imperativos categóricos, a tener una única gran obligación de hacer: dejar al otro ser.

Esta gran obligación reemplaza el libre albedrío y configura lo que Levinas llama el juicio ético. Levinas identifica el rostro y sobretodo la mirada, con una forma de lenguaje. Es un símbolo, expresa algo. Es un Ilamado ineludible y enfrentarse a un rostro crea responsabilidad y cuestiona la capacidad de hacer de cada quién, la libertad de cada quien. Así, en el juicio ético el

2 En este punto es útil pensar la forma como Levinas comprende "al otro" como un fenómeno, siguiendo la tradición de Husserl, en la que descubrir lo esencial de cualquier objeto nos es imposible pues todo lo que sabemos de él viene de nuestros sentidos, son impulsos que dibujan algo imperfecto, un fenómeno, pero sin revelarnos la verdadera esencia del ser de algo. Para Levinas, el otro es también una suerte de fenómeno pero con la particularidad de que la mirada y la palabra tienden un puente entre los núcleos de fenómenos (personas) que de lo contrario estarían infinitamente alejados de sí.

3 No en vano, el elemento esencial del Debido proceso es que el procesado pueda exponer ante un tribunal imparcial las circunstancias que desde su punto de vista rodearon un hecho dado para poder probar su inocencia, que actuó por fuerza mayor o, por el contrario, que efectivamente sus acciones son condenables desde un parámetro de comportamiento objetivo. Desde la ética de Levinas esto es imposible porque conocer la totalidad de "las circunstancias" del otro para emitir un juicio justo es imposible. límite de la libertad de actuar de cada quien es el rostro de otro. Quiere decir que, al percibir el símbolo de otro, quedamos limitados en nuestra acción a responder al reconocimiento de esa infinita diferencia y, de alguna manera, a respetarla porque es sagrada. El irrespeto de ese llamado es inmoral. En la Segunda Guerra Mundial, el rostro de cada judío era evidente pero la noción de la identidad como ética enmudecía ese llamado. La fuerza del argumento de Levinas está en que el llamado se hace desde la diferencia, desde lo incomprensible y, justo por eso, desde lo sagrado (Levinas, 2002, pág. 211).

\section{LA PROPUESTA}

Ahora, ¿es posible conciliar una ética así con el derecho, siendo que el derecho es la expresión de la política - es el que gana en la guerra o en la política el que dicta el derecho-y para Levinas la política es hija de la guerra?, ¿cómo, además, si Levinas sospecha del libre albedrío y del individualismo, fundamento del consentimiento? Pues bien, justamente porque son teóricamente inconciliables es que propongo esta ética como una óptica desde la cual puede evaluarse y medirse el nivel ético de un ordenamiento jurídico. En efecto, como son inconciliables, no pretendo ni propongo que estos fundamentos sean asumidos por el ordenamiento jurídico como propios, a diferencia de lo que ha sucedido, afortunadamente, con otros sistemas éticos que han servido, tanto para criticar como para orientar e inspirar teorías del Estado y del derecho. Ejemplos de lo anterior los encontramos desde Kant y Locke hasta la más moderna Hannah Arendt. 
En efecto, el derecho actual, el occidental al menos, está inundado de nociones éticas tradicionales. Los preámbulos a las constituciones, a las declaraciones de derechos, todos esos documentos -que, por cierto, surgieron entre otras y al igual que la ética de Levinas como respuesta urgente a lo sucedido en la Segunda Guerra Mundial- Ilevan mezclados en sí nociones éticas (libertad, respeto, reconocimiento) que hacen la división, en la vida diaria, entre ética y derecho cada vez más difícil. ${ }^{4}$ En realidad, la ética occidental pasó a ser un limitante externo al derecho para ser su fuente de alimento. $Y$ eso, lejos de ser un problema, hace que los ordenamientos jurídicos procuren ser más justos. Pero, cabe preguntarse por la posibilidad de buscar y encontrar otras visiones éticas para probar y retar constantemente nuestros ordenamientos jurídicos y la forma como nos aproximamos a ellos para seguir perfeccionándolos y cambiándolos según lo requiera la evolución misma de las sociedades. ${ }^{5}$

4 En Colombia, por ejemplo, hay una marcada tendencia a ver a la Corte Constitucional como máximo tribunal defensor de la "justicia" que protege a los desvalidos, lucha por los débiles. No creo que esto tenga nada de malo, por el contrario, habla muy bien de nuestro derecho constitucional. No obstante, habría que preguntarse si es posible que desapercibidamente algún día empezáramos a interpretar lo ético o justo como lo que dice la Corte y no como es ahora, como ético o justo, lo que dice la Corte.

5 Un ejemplo interesante se encuentra en las crónicas de un Viaje a la selva, que Héctor Abad Faciolince publicó en El Espectador en julio del 2012. En estas, el autor se pregunta - luego de una visita a una comunidad indígena en el Amazonas- sobre la posibilidad de que no sea deseable bajar la mortalidad infantil en la selva, dadas las condiciones en que estos pueblos deben sobrevivir. Si bien Abad no se decide a responder, este es un excelente ejemplo de cómo algo que, a los ojos occidentales parece una máxima evidente ("procurar proteger la vida de los niños"), en la selva puede, incluso, ser necesario que el $20 \%$ de los menores de cinco años mueran de alguna infección. Si bien a mí personalmente me cuesta pensarlo, es un ejercicio interesante (Abad Faciolince, 2012).
Es difícil -quizás incluso indeseable-que el postulado de la alteridad de Levinas sea uno que un sistema jurídico pueda asumir como premisa, pero sí es un llamado a asumir el sistema con humildad y cautela. Como se dijo anteriormente, de este postulado surge la casi imposibilidad de emitir cualquier juicio real -salvo el ético, el más fuerte de todos-sobre las acciones de alguien y a la hora de regular una sociedad moderna, son más los juicios que deben emitirse, no solo la máxima "no matarás". Así, no es en vano que el derecho civil se inventó hace muchísimo tiempo "la responsabilidad objetiva", entendida como la responsabilidad que surge de violar un parámetro, un comportamiento deseable en la vida en sociedad, sin atender realmente a las circunstancias particulares de cada cual, salvo en casos extremos, como el derecho penal. Dichos parámetros de conductas deseables surgen de prácticas históricas o por medios incluyentes y deliberativos, y el sistema vela por su cumplimiento. Eso no es, sin embargo, un juicio al individuo, a la persona.

La ventaja de hacer la división ética-jurídica es que el derecho juzga las acciones individuales de cada quién (y cada quién responde por ellas), mientras que la ética se ocupa de mantener la sacralidad de cada uno de nosotros, es un plano simultáneamente más compasivo y, simultáneamente el más severo, pues emite ese único juicio posible, pero el más fuerte de todos, sobre las personas. Mantenida esta división, la ética salva la esencia del individuo de las garras del sistema jurídico y le permite a este juzgar las acciones estrictamente, pues es un juicio 
aislado y pactado, que no pretende condenar la individualidad de cada quien sino las acciones indeseables. Desde la ética también se puede juzgar el sistema jurídico y a sus operadores, como esfera aparte e independiente, y así constituir el límite último a su ejercicio, desde el más profundo respeto a la diferencia del otro.

\section{UN ESTUDIO DE CASO: ATTICUS FINCH}

Atticus Finch, uno de los personajes más importantes de la novela de la americana Harper Lee, Matar un ruiseñor, es, a mi modo de ver, un ejemplo de este tipo de aproximación al otro. La historia tiene lugar en un pequeño pueblo de Alabama, Estados Unidos, en los años 30, y Atticus, el padre del personaje principal de la historia, una niña Ilamada Scoutt, es un conocido abogado allí. Un verano, un joven afro, manco, es acusado de violar y golpear a una chica blanca que viene de una familia muy humilde y problemática, cuyo padre es conocido en el pueblo por ser alcohólico y violento. Atticus asume la defensa del joven quien, a pesar de ser inocente, tiene todas las de perder debido a su color de piel, aunque en el juicio se demuestra que quien en realidad golpeó a la chica fue su padre.

Durante el juicio, luego de interrogar en la Corte a Bob Ewell, el padre de la chica supuestamente violada, este se encuentra con Atticus en la calle y le escupe a la cara. Scout le manifiesta su indignación a su padre. La respuesta que él le da es un ejemplo de la aproximación ética que propongo:
Jem see if you can stand in Bob Ewell's shoes a minute. I destroyed his last shred of credibility at that trial, if he had any to begin with. The man had to have some kind of comeback, his kind always does. So if spitting in my face and threatening me saved Mayella Ewell one extra beating, that's something I'll gladly take. He had to take it out on somebody and l'd rather it be me than that household full of children out there. (Lee, 1960).

Atticus procede en dos planos: por un lado, y en lo público, está su labor como litigante, en la que debe probar los hechos que soportan su caso y mostrar que el Sr. Ewell miente, ese es su plano jurídico. Está, por otro, un plano moral, en su conciencia y en privado, en el que no se siente capaz de juzgar verdaderamente al Sr. Ewell. Sabe que su vida es bastante difícil y que las razones que lo llevan a actuar de una u otra manera son demasiado abrumadoras como para que él pueda reprobarlas con alguna autoridad y decir "es que todos somos iguales", "es que tenemos libre albedrio". Desde este plano Atticus toma distancia y atiende el llamado del otro. A lo mejor por eso es que, en el libro, uno nunca percibe un Atticus bravo, sino uno triste, uno compasivo. Eso es lo que le transmite a sus hijos.

\section{EL CÍRCULO DE LA PALABRA Y CONCLUSIÓN}

Ahora, la intención inicial de este ensayo era proponer una alternativa a la evaluación de un ordenamiento jurídico cada vez más justo, pero que no cayera en la trampa de medir su justicia 
con los propios parámetros que consagró como principios, como una serpiente que muerde su cola. Por eso la necesidad de un nuevo rasero y la propuesta de utilizar para ello la ética de Levinas. Así, la última pregunta es quizá la más importante, ¿cómo alimentar de esa ética tan distinta un sistema jurídico o la práctica jurídica en general?

Como mencioné al principio, Levinas propone como momentos de contacto la palabra y el rostro. Pero de hecho, el encuentro de la palabra y el rostro entre personas es, quizá, una de las prácticas humanas más antiguas, quizá el inicio de toda comunidad. Los indígenas lo Ilaman "círculo de la palabra", pero también antaño se le Ilamaba asamblea o, por qué no, misa. Es la práctica milenaria de sentarse y hablar alrededor de un fuego y contar historias, ese momento en el que otros diferentes se re-conocen los unos a los otros, se obsequian los unos a los otros palabras o silencio - no hay que olvidar que la palabra es mitad silencio y mitad sonido- y tejen lazos entre sí. En la modernidad también lo conocemos: le decimos fogata en los campos de verano, tertulia cuando es a media noche entre amigos o, incluso, sobremesa. Lo importante es hablar desde el corazón y escuchar con el alma, sin juzgar, sin aparentar. Es de estos lazos que surge luego una comunidad, el deseo honesto de construir para un "nosotros" distintos, pero mágicamente unidos. Una sociedad que, más adelante, necesitará de un sistema jurídico.

Mi conclusión no es, entonces, ajena a los ordenamientos que tenemos, ni innovadora en absoluto. Mi conclusión no es otra sino que el derecho no puede ser sordo ni ciego. El derecho -pero sobre todo sus operadores, pues al fin de cuentas somos nosotros quienes lo creamos en el día a día-, no puede creerse completo ni infalible porque ha logrado acumular una serie de principios que consideramos adecuados. Ya decía Savigny que condenamos el derecho a morir cuando intentamos hacer que deje de cambiar. Mi conclusión es más un llamado a la humildad y a escuchar con atención la próxima vez que se nos aparezca -y que con seguridad no será lejana - una mujer que decida usar un velo para taparse la cara porque así lo quiso su Profeta, un hombre indígena que diga que llevar medicamentos a la selva es atentar contra su cultura o un abuelo que insista en que la familia es lo más importante que hay y que todos debemos casarnos y tener hijos. No se trata de tolerar, pues tolerar tiene un amargo sabor a soportar algo tedioso sin quejarse. Se trata de escuchar y permitir que de ese diálogo surjan vínculos entre las personas, vínculos cuasi-fraternales que luego inspiren las reglas de la sociedad, y eventualmente el derecho. Se trata de no dejar de escuchar, aun cuando duela o cuando amenace lo que nosotros mismos creemos, y permitir que esa escucha sea latente en el derecho. Al fin de cuentas es de ese mismo diálogo del que trata la democracia.

Me imagino que entonces existe la posibilidad de que sintamos que vamos en un barco a la deriva en medio de una tormenta - sin libre albedrío, sin alguien como nosotros en quien aferrarnos- pero creo también que así se tienden lazos más fuertes. Lazos que nos sostengan a pesar de todo, a pesar incluso de ser diferentes. 
Referencias Abad Faciolince, H. (julio 1 de 2012). Viaje a la selva. El Espectador.

Levinas, E. (2002). Totalidad e infinito: ensayo sobre la exterioridad. Salamanca: Ediciones Sígueme.

Lee, H. (1960). To kill a Mockingbird. New York: Pinguin Books. 